UDC 616-008.9:612.392.64-022.252-08(476)

DOI: $10.21668 /$ health.risk/2019.1.06.eng

Read

online

\title{
RISK COMMUNICATION AS A COMPONENT THAT PROVIDES STABILITY OF STRATEGY AIMED AT ELIMINATING DISEASES CAUSED BY IODINE DEFICIENCY IN BELARUS
}

\author{
E.V. Phedorenko ${ }^{1}$, N.D. Kolomiets ${ }^{2}$, T.V. Mokhort ${ }^{3}$, A.N. Volchenko ${ }^{1}$, \\ E.G. Mokhort ${ }^{3}$, S.V. Petrenko ${ }^{4}$, S.I. Sychik ${ }^{1}$ \\ ${ }^{1}$ Scientific-Practical Hygiene Center, 8 Akademicheskaya Str., Minsk, 220012, Belarus \\ ${ }^{2}$ Belarus Medical Academy for Post-graduate Studies, 3/3 P. Brovki Str., Minsk, 220013, Belarus \\ ${ }^{3}$ Belorusskiy State Medical University, 83 Dzerzhinskiy av., Minsk, 220116, Belarus \\ ${ }^{4}$ A.D. Sakharov's International State Ecological Institute, 23/1 Dolgobrodskaya Str., Minsk, 220070, Belarus
}

There is a strategy being implemented now in Belarus that involves obligatory application of high quality iodized salt in food industry; it has resulted in iodine deficiency elimination among population. Sales of iodized salt account for more than $70 \%$ of the overall salt sales in retail outlets. However, attention paid to the issue has started to decline recently, including mass media; at present there is no social advertising that informs people about iodized salt being useful for their health. Our research object was population awareness about various aspects related to prevention of diseases caused by iodine deficiency and objective indicators of iodine provision. Our research goal was to determine probable risks of iodine deficiency prophylaxis becoming less efficient and to substantiate ways how to prevent negative trends.

Data and methods. We assessed population awareness on iodine deficiency via questioning; overall, 805 people living in Belarus took part in it. Alimentary exposure to iodine was calculated for various scenarios taking into account natural iodine contents and artificially added iodine in food products as well as consumption volumes. Ioduria was assessed with cerium-arsenite technique. We considered dynamics in morbidity with simple goiter and congenital hypothyroidism to be indicators of iodine provision. Basic results. We detected that most respondents, $658(81.7 \%$, $95 \%$ CI 78.8-84.7) to be exact, thoughts that their therapists were the primary source of knowledge on health-related issues; $176(21.9 \%, 95 \%$ CI 15.8-28.0) trusted mass media including the Internet. More than half respondents $(61.4 \%, 95 \%$ CI 60.8-62.0\%) and medical personnel statistically significantly more frequently $(77.1 \%, 95 \%$ CI $70.7-83.61 \%)$ believed there was a iodine deficiency problem existing in the country.

We didn't detect any risk of excessive iodine introduction with food products. Selective monitoring over ioduria among children proves their iodine provision is quite appropriate as it amounts to more than $100 \mu \mathrm{g} / \mathrm{l}$. Dynamics of primary morbidity with congenital hypothyroidism confirms that stable positive results have been achieved in the sphere; in 2006 primary morbidity was equal to 1.96 per 100 thousand people, but in 2017 it dropped to 0.96 per 100 thousand people. It proves that Belarus is among countries where population consume proper amounts of iodine. But an arising trend for lower awareness about iodine deficiency calls for more active risk communication about possible diseases related to iodine deficiency, including mass media campaigns.

Key words: iodine, iodized salt, monitoring, diseases caused by iodine deficiency, risk communication.

(C) Phedorenko E.V., Kolomiets N.D., Mokhort T.V., Volchenko A.N., Mokhort E.G., Petrenko S.V., Sychik S.I., 2019

Ekaterina V. Phedorenko - Candidate of Medical Sciences, Associate Professor, Deputy Director responsible for support of practical sanitary-epidemiologic surveillance and work with the Eurasian Economic Commission (e-mail: afedorenko71@mail.ru; tel. +375 172-84-13-65; ORCID: http://orcid.org/0000-0003-1240-1234).

Natalia D. Kolomiets - Doctor of Medical Sciences, Professor, Head of the Department for Epidemiology and Microbiology (e-mail: ndkolomiets@mail.ru; tel. +375 293-54-39-04; ORCID:http://orcid.org/0000-0002-4837-5181).

Tatyana V. Mokhort - Doctor of Medical Sciences, Professor, Head of the Endocrinology Department (e-mail: tat_mokh@mail.ru; tel. +375 296-36-52-82; ORCID: http://orcid.org/0000-0002-5040-3460).

Alina N. Volchenko - Candidate of Medical Sciences, Associate Professor at the Department for Epidemiology and Microbiology (e-mail: libertatta@gmail.com; tel. +375 447-73-33-83; ORCID: https://orcid.org/0000-0002-0133-0904).

Elena G. Mokhort - Candidate of Medical Sciences, Associate Professor at the Endocrinology Department (e-mail: al_mokhort@mail.ru; tel. +375 296-78-87-72; ORCID: http://orcid.org/0000-0002-6748-9598).

Sergey V. Petrenko - Candidate of Medical Sciences, Associate Professor, Head of the Research Laboratory for Anthropoecology and Public Health (e-mail: petrenko51@yahoo.com; tel. +375 256-12-14-10; ORCID: http://orcid.org/0000-0001-6248-4619).

Sergey I. Sychik - Candidate of Medical Sciences, Associate Professor, Head of the Scientific-Practical Hygiene Center (e-mail: respch@rspch.by; tel. +375 172-84-13-70; ORCID: http://orcid.org/0000-0002-5493-9799). 
Introduction. Iodine is an essential element with great biological significance. If it isn't naturally introduced in a body in sufficient quantities, it results in certain iodine deficiency disorders (IDD), such as thyroid gland diseases, miscarriages, greater perinatal mortality and risk of physical and mental retardation among children, and endemic cretinism. Incidence in this case is correlated to quantitative distribution of iodine in the environment in a specific region [1]. According to WHO data, about $1 / 3$ of the overall world population suffer from insufficient introduction of iodine and it causes serious threats for public health. In spite of serious outcomes IDD might have they can be quite successfully prevented, and there are not so many social and medical problems that can be solved such easily [2, 3]. Global efforts made by the world society have substantially changed geography of IDD prevalence; use of iodized salt in households has been recognized as a basic way to fight the above-mentioned morbid state. In relation to that, many countries have changed their national legislation related to regulation of population nutrition. However, such a radical way hasn't been eventually supported by all the countries in the world, either due to moral and ethical reasons (freedom of choice), or economic and political ones $[4,5]$.

Iodine alimentary insufficiency is vital for Belarus as well and it is confirmed by historically known regions in the country that are endemic as per goiter; the situation is caused by geochemical iodine deficiency in soils (within $0.1-9.23 \mathrm{mg} / \mathrm{kg}$ ) and drinking water $\left(1.9-3.2 \mu \mathrm{g} / \mathrm{dm}^{3}\right)$. As the country is located far from any sea, population traditionally tend to consume low quantities of sea fish and sea food that could naturally eliminate any iodine deficiency [6]. Research that was accomplished at the end of the last century, including that supported by WHO/UNICEF, revealed that ioduria median amounted to $44.5 \mu \mathrm{g} / 1$, and endemic goiter prevalence among children reached $28.0-30.0 \%$. These data again indicated it was necessary to investigate iodine deficiency in the country and to work out and implement some actions in this respect. In 2000 the Belarus Public Healthcare Ministry started to work out and implement an unique national strategy aimed at eliminating iodine deficiency; it was based on the following principles:

- making alterations into The State Standards issued in Belarus that fixed the requirements to iodine concentration in iodized salt as being equal to $40 \pm 15 \mathrm{mg} / \mathrm{kg}$;

- applying potassium iodate instead of potassium iodide to iodize salt as it allowed to substantially improve iodine preservation and culinary properties of food;

- obligatory application of iodized salt in food products manufacturing and in catering, including nutrition arranged for children and adults in pre-school facilities, schools, and various establishments;

- information campaigns for population at all levels;

- medical and social-hygienic monitoring.

Iodine Global Network has created certain efficiency indicators that are usually applied to assess national programs; they include median for iodine excretion with urine that should excess $100 \mu \mathrm{g} / \mathrm{l}$ in schoolchildren and pregnant women at a national and/or subnational level, or assessment of a share that belongs to qualitative iodized salt on the consumer market and in industry. In 2013 these indicators were analyzed as regards the prevention program in Belarus, and the results allowed experts to recommend the International Council for Control of Iodine Deficiency Disorders (ICCIDD) to assign Belarus into a group of countries with adequate iodine provision [7]. Elimination of iodine deficiency in nutrition doesn't lead to immediate IDD elimination as it usually takes several years of persistent efforts to detect a decrease in endemic goiter prevalence among population who were born and have been permanently living in a specific biogeochemical province. However, if activities are controlled sporadically or there is no control at all, it results in poorer iodine provision and a growth in incidence with IDD. Therefore, to assess efficiency and to support stability of an IDD prevention program, international expert organizations recommend to perform regular 
monitoring over implemented activities as per all the necessary components $[8,9,10]$.

Given all the above-mentioned, we chose a research goal that was to determine possible risks of a decrease in IDD prophylaxis efficiency and to substantiate ways which were necessary to prevent any negative trends in the sphere.

We solved the following tasks:

- performed a complex examination of people awareness about iodine deficiency and their attitudes towards iodized salt consumption;

- calculated alimentary exposure to iodine taking into account different ways of its introduction into a body;

- assessed iodine provision as per ioduria monitoring, dynamics of morbidity with simple goiter and primary congenital hypothyroidism.

Data and methods. To assess awareness people had about IDD and their attitudes towards that issue, we took a questionnaire recommended by WHO (with certain supplements) for epidemiologic research applied in Belarus since 1997. Overall, we questioned 805 people living in Belarus, in Minsk and other regions. To assess alimentary exposure to iodine, we calculated its introduction taking into account both background concentrations and iodized products; we applied frequency analysis to estimate consumption of food products with natural iodine contents, food products manufactured with iodized salt, and consumption of food products enriched with iodine as well.

We determined iodine excretion with urine with spectrophotometric cerium-arsenite technique accepted by WHO as a conventional international method [11].

Accomplished research allowed us to create a computer database in EXCEL - XP. The obtained data were statistically processed with STATISTICA 6.0 applied software. The questioning results are given as $\%$ with $95 \%$ confidence interval $(95 \% \mathrm{CI})$. Research on incidence with simple goiter and primary congeni- tal hypothyroidism was performed on the basis of data taken from the state statistical reports ${ }^{1}$.

Results. Nowadays people can quite easily get an access to any information on how to preserve their health, healthy lifestyle, rational nutrition, or certain products that should be included into their daily ration. However, if people don't have any specialized training or education, it is sometimes rather difficult for them to figure these issues out on their own and to come to a correct opinion; and it is even harder to adhere to relevant principles.

We naturally assumed that medical workers should be better aware how to preserve health than respondents with any other occupation. For this reason, when analyzing the questioning results, we created two groups; the first one consisted of 594 people without medical education who didn't work at any healthcare organization, and the second one included 210 people with medical or biological education and an occupation related to providing medical aid (medical or healthcare workers).

The results revealed that most respondents thought their attending medical doctors to be the basic source of information on how to preserve health as such an answer was given by 658 people $(81.7 \%, 95 \%$ CI $78.8-84.7)$, and the share of positive responses didn't differ significantly in groups 1 and 2 and amounted to $83.9 \%(95 \% \mathrm{CI} 80.6-87.1)$ and $75.7 \%(95 \%$ CI 69.0-82.4) respectively. Other important sources of information included the Internet, 176 people $(21.9 \%, 95 \%$ CI $15.8-28.0)$; printed editions, 118 people $(14.7 \%, 95 \%$ CI $8.3-21.0)$; TV, 80 people $(9.9 \%, 95 \%$ CI $3.4-16.5 \%)$. The least trust was put by our respondents into relatives, friends, and other sources of information, from $1.5 \%$ to $7.0 \%$ (95\% CI $0.0-13.6 \%)$. There was a question who bore the greatest responsibility for prevention of non-infectious diseases, including cardiovascular system diseases and endocrine system diseases; most respondents inclined to think the responsibility was utterly their own as 678 people $(84.2 \%$,

\footnotetext{
1 "The Report on number of diseases registered in patients aged 18 and older, living on a territory on which medical; services are rendered by a healthcare organization in 20 _ ", approved by the Order by Belarus National Statistical Committee on October 08, 2012 No. 168, with amendments made on August 11, 2017 No. 90.[web-source]. - URL: http://www. belcmt.by/ru/activity-of-the-center/statistika/state-statistical-reporting (date of visit November 12, 2018).
} 
95\% CI 81.5-87.0) gave this answer. There were other popular answers, for example, "medical staff should do it", 196 people $(24.4 \%$, 95\% CI 18.3-30.4), or "the state", 130 people $(16.2 \%$, 95\% CI 9.8-22.5\%). A rather small number of respondents, 30 people $(3.7 \%, 95 \%$ CI $0.0-10.6)$ thought that "local authorities" should take care of their health, and only 8 people $(1.0 \pm 0.3 \%)$ $(1.0 \%, 95 \%$ CI $0.0-8.3 \%)$ stated that the above-mentioned diseases "couldn't be prevented". We didn't reveal any significant discrepancies between answers given by people from two different groups. In spite of quite a big number of respondents - 84.2\% (95\% CI $81.5-87.0 \%$ ) - thinking that taking care of their health was their own responsibility, only 258 of them $(32.1 \%, 95 \%$ CI $26.4-37.7 \%)$ controlled their blood pressure regularly and on their own, without any doctor's recommendations. 287 respondents $(35.7 \%$, 95\% CI 30.1-41.2\%) showed interest in this health parameter when they visited a doctor; 260 respondents $(32.3 \%$, 95\% CI 26.6-38.0) didn't controlled it. Only one fourth of 258 people $(24.4 \%, 95 \%$ CI $13.8-35.0 \%$ ) who controlled their blood pressure were medical workers. Therefore, correct "theoretical" understanding that it is necessary to take care of one's health wasn't put into practice even regarding a simplest issue, control over blood pressure, and the situation was the same either for medical workers or people with any other occupation.

Table 1 contains the results regarding awareness that respondents have about iodine deficiency. 156 people of the overall sampling (19.4\%, 95\% CI 13.2-25.6\%) stated that they or their relatives who lived with them had thyroid gland diseases, 111 people in group 1 $(13.8 \%, 95 \%$ CI $7.4-20.2 \%)$, and 45 people (5.6\%, 95\% CI $0.0-12.3 \%)$ in group 2. More than a half respondents thought that there was a problem related to iodine deficiency in our country as 494 people gave such an answer (61.4\%, 95\% CI 60.8-62.0\%), and here statistically significantly greater share of medical workers were of this opinion, $162(77.1 \%$, $95 \%$ CI $70.7-83.6 \%$ ) in group 2 against 332 (55.8\%, 95\% CI 50.5-61.1\%) against group 1 . We should note that according to a national questioning accomplished in $2003,74 \%$ out of 5,000 respondents knew there was a iodine deficiency in Belarus, and $87 \%$ saw advertising on TV that was urging them to consume iodized salt [12]. It proves that awareness on IDD issues among population has decreased. And, taking into account priority sources of information mentioned by our respondents, we should assume that TV advertising won't have any substantial influence on consumers awareness on necessity to prevent alimentary iodine deficiency.

There was a question whether a person could control iodine consumption on his or her own making it sufficient; 495 respondents (61.5\%, 95\% CI 60.9-62.1) answered "yes", and these answers were quite in line with those given to the previous question in both groups. Eventually, 159 medical workers $(75.7 \%, 95 \%$ CI 69.0-82.4) were statistically significantly more self-confident than 336 people who didn't work at a medical organization $(56.5 \%$, 95\% CI 51.2-61.7\%). There was statistically significantly smaller number of medical workers who had difficulty answering this question, (8.1\%, 95\% CI $0.0-21.5 \%)$, than people who didn't work at any medical organization (27.7\%, 95\% CI 20.9-34.6). And quite similar number of people in both groups believed they couldn't solve this problem themselves (15.8\%, 95\% CI 8.4-23.2 and 16.2\%, 95\% CI $3.8-28.6 \%$, respectively).

More than half respondents (440 people or $55 \%, 95 \%$ CI 54.1-55.3) stated it was impossible to eliminate iodine deficiency by consuming only "local" products; however, statistically significantly more medical workers knew it (164 people or $78 \%, 95 \%$ CI $71.8-84.4$ ).

Medical workers were naturally better aware of health disorders caused by iodine deficiency and its insufficient introduction into a body (such as lower intelligence, endemic goiter, or chronic fatigue) than people in group 1 or the overall sampling (Table 1). However, only $28 \%$ of medical workers $(95 \%$ CI 16.1-39.1) and $16 \%$ of other respondents (95\% CI 8.4-23.4) stated that iodine deficiency could be an obstacle for pregnancy (as it causes infertility); so, as we can see, only 
Table 1

Assessment of awareness on iodine deficiency among people living in Belarus

\begin{tabular}{|c|c|c|c|c|c|c|c|c|c|}
\hline \multirow{2}{*}{$\begin{array}{l}\text { Question / } \\
\text { Answer to it }\end{array}$} & \multicolumn{3}{|c|}{ Total } & \multicolumn{3}{|c|}{ Not related to medicine } & \multicolumn{3}{|c|}{ Medical workers } \\
\hline & abs. & $\%$ & $\mathrm{CI}$ & abs. & $\%$ & CI & abs. & $\%$ & $\mathrm{CI}$ \\
\hline \multicolumn{10}{|c|}{ Do you / you relatives who live with you have any thyroid gland diseases? } \\
\hline Yes & 156 & 19 & $13.2-25.6$ & 111 & 19 & $11.4-25.9$ & 45 & 21 & $9.4-33.4$ \\
\hline No & 649 & 81 & $77.6-83.6$ & 484 & 81 & $77.9-84.8$ & 165 & 79 & $72.3-84.8$ \\
\hline \multicolumn{10}{|c|}{ Do you think there is iodine deficiency in Belarus? } \\
\hline Yes & 494 & 61 & $60.8-62.0^{* *}$ & 332 & 56 & $50.5-61.1^{*}$ & 162 & 77 & $70.7-83.6^{*}$ \\
\hline No & 87 & 11 & $4.3-17.3$ & 66 & 11 & $3.5-18.7$ & 21 & 10 & $0.0-23.1$ \\
\hline Difficult to say & 224 & 28 & $21.9-33.7$ & 197 & 33 & $26.5-39.7^{*}$ & 27 & 13 & $0.0-25.7^{*}$ \\
\hline \multicolumn{10}{|c|}{ Can people see to sufficient consumption of iodine themselves? } \\
\hline Yes & 495 & 62 & $60.9-62.1^{* *}$ & 336 & 56 & $51.2-61.8^{*}$ & 159 & 76 & $69.0-82.4^{*}$ \\
\hline No & 128 & 16 & $9.56-22.2$ & 94 & 16 & $8.4-23.2$ & 34 & 16 & $3.8-28.6$ \\
\hline Difficult to say & 182 & 22 & $16.5-28.7$ & 165 & 28 & $20.9-34.6$ & 17 & 8 & $0.0-21.5$ \\
\hline \multicolumn{10}{|c|}{$\begin{array}{l}\text { Do you know that if you consume only local food (grown and manufactured in Belarus) } \\
\text { it will not provide you with essential quantity of iodine? }\end{array}$} \\
\hline Yes & 440 & 55 & $54.1-55.3^{* *}$ & 276 & 46 & $40.5-52.3^{*}$ & 164 & 78 & $71.8-84.4^{*}$ \\
\hline No & 348 & 43 & $42.6-43.9^{* *}$ & 304 & 51 & $45.3-56.7^{*}$ & 44 & 21 & $8.9-33.0^{*}$ \\
\hline Difficult to say & 18 & 2 & $0.0-9.3$ & 16 & 3 & $0.0-10.9$ & 2 & 1 & $0.0-20.0$ \\
\hline \multicolumn{10}{|c|}{ What health disorders are caused by iodine deficiency? } \\
\hline Excess weight & 198 & 25 & $18.6-30.6$ & 151 & 25 & $18.4-32.3$ & 47 & 23 & $10.5-34.3$ \\
\hline Lower intelligence & 280 & 35 & $29.2-40.4^{* *}$ & 162 & 27 & $20.4-34.4^{*}$ & 118 & 56 & $42.2-65.1^{*}$ \\
\hline Growth retardation & 248 & 31 & $25.1-36.6$ & 157 & 26 & $19.5-33.3$ & 91 & 43 & $33.2-53.5$ \\
\hline Infertility & 152 & 19 & $12.7-25.1$ & 94 & 16 & $8.4-23.4$ & 58 & 28 & $16.1-39.1$ \\
\hline Endemic goiter & 571 & 71 & $67.2-74.7^{* *}$ & 384 & 65 & $59.8-69.3^{*}$ & 187 & 89 & $84.6-93.5^{*}$ \\
\hline Chronic fatigue & 457 & 57 & $56.2-57.4^{* *}$ & 313 & 53 & $47.1-58.1^{*}$ & 144 & 69 & 61.0-76.2* \\
\hline Other & 15 & 2 & $0.0-8.9$ & 10 & 2 & $0.0-10.1$ & 5 & 2 & $0.0-17.3$ \\
\hline Difficult to say & 42 & 5 & $0.0-12.0$ & 41 & 7 & $0.0-14.0$ & 1 & 0.5 & $0.0-14.0$ \\
\hline \multicolumn{10}{|c|}{ Do pregnant and breast-feeding women need to consume iodine in greater quantities? } \\
\hline Yes & 505 & 63 & $62.2-63.3^{* *}$ & 345 & 58 & $52.8-63.2^{*}$ & 160 & 76 & $69.6-82.8^{*}$ \\
\hline No & 42 & 5 & $0.0-12.0$ & 26 & 4 & $0.0-12.4$ & 16 & 8 & $0.0-21.1$ \\
\hline Difficult to say & 258 & 32 & $26.4-37.7$ & 224 & 38 & $31.3-44.0^{*}$ & 34 & 16 & $3.8-28.6^{*}$ \\
\hline
\end{tabular}

Note: * means discrepancies between groups 1 and 2 are statistically significant, $p \leq 0.05$;

** means discrepancies in a number of answers given by overall sampling are statistically significant in comparison with a number of answers given by medical workers, $\mathrm{p} \leq 0.05$.

152 people in the overall sampling $(19 \%, 95 \%$ CI 12.7-25.1) fully realized how grave the problem was. But at the same time $2 / 3$ or 505 respondents (63\%, 95\% CI 62.2-63.3) knew that pregnant women and breast-feeding mothers needed to consume iodine in greater quantities; and 224 (86.8\%, 95\% CI 82.3-91.3\%) out of 258 people who had difficulty answering this question didn't have any medical education.

Table 2 contains answers given to questions on activities that are applied to prevent iodine deficiency. Only 134 respondents (17\%,
95\% CI 10.3-23.0\%) agreed that consumption of table iodized salt was enough for preventing iodine deficiency, $15 \%$ from group 1 , and $21 \%$ from group 2: About half of total 805 respondents, 420 people $(52 \%, 95 \%$ CI $51.6-52.8 \%)$ thought that iodized salt only wasn't enough to prevent iodine deficiency. And there were statistically significantly more respondents in group 1 than among medical workers who were sure iodized salt consumption was enough to make up for iodine concentration in a body or who had difficulty answering this 
Table 2

Ways to prevent iodine deficiency in households

\begin{tabular}{|c|c|c|c|c|c|c|c|c|c|}
\hline \multirow{2}{*}{$\begin{array}{c}\text { Answer } \\
\text { to a question }\end{array}$} & \multicolumn{3}{|c|}{ Total } & \multicolumn{3}{|c|}{ Not related to medicine } & \multicolumn{3}{|c|}{ Medical workers } \\
\hline & abs. & $\%$ & $\mathrm{CI}$ & abs. & $\%$ & $\mathrm{CI}$ & abs. & $\%$ & $\mathrm{CI}$ \\
\hline \multicolumn{10}{|c|}{ Can iodized salt consumption completely eliminate iodine deficiency in a body? } \\
\hline Yes & 134 & 17 & $10.3-23.0$ & 89 & 15 & 7.6-22.4 & 45 & 21 & $9.4-33.4$ \\
\hline No & 420 & 52 & $51.6-52$. & 289 & 49 & $42.8-54.3^{*}$ & 131 & 10 & $3.1^{*}$ \\
\hline Difficult to say & 251 & 31 & $25.5-36.9$ & 217 & 36 & $30.1-42.9^{*}$ & 34 & 13 & $0.0-25.7^{*}$ \\
\hline \multicolumn{10}{|c|}{ What do you apply to eliminate iodine deficiency in a body? } \\
\hline lodized salt & 392 & 49 & $48.1-49.3^{* *}$ & 259 & 44 & $37.5-49.6^{*}$ & 133 & 63 & $55.1-71.5^{*}$ \\
\hline $\begin{array}{l}\text { BAA to food or } \\
\text { tivitamin prepar }\end{array}$ & 171 & 21 & $15.1-27.4$ & 112 & 19 & $11.6-26.1$ & 59 & 28 & 16.3-39.6 \\
\hline Sea food & 471 & 59 & $57.9-59.1^{* *}$ & 336 & 19 & $51.2-61.8^{*}$ & 135 & 64 & $16.3-39.6^{*}$ \\
\hline Nalnuts a & 226 & 28 & $22.2-33.9$ & 167 & 57 & 21.3-34.9 & 59 & 28 & $16.3-39.6$ \\
\hline ther products rich & 236 & 17 & $11.1-23.7$ & 224 & 17 & $9.5-24.1$ & 74 & 19 & $6.9-21.4$ \\
\hline Nothing & 96 & 12 & $5.5-18.4$ & 82 & 14 & $6.3-21.2$ & 14 & 7 & $0.0-20.2$ \\
\hline
\end{tabular}

Note: * means discrepancies between groups 1 and 2 are statistically significant, $p \leq 0.05$;

** means discrepancies in a number of answers given by overall sampling are statistically significant in comparison with a number of answers given by medical workers, $\mathrm{p} \leq 0.05$.

question. 392 respondents $(49 \%, 95 \%$ CI 48.1-49.3) consumed iodized salt, but in addition to it, respondents also mentioned sea food (471 people, $58.5 \%, 95 \%$ CI 57.9-59.1\%), biologically active additives to food (BAA) or multivitamin preparations (171 people, $21.2 \%$, CI 15.1-27.4\%), walnuts (226 people, $28.1 \%$, $95 \%$ CI $22.2-33.9 \%$ ), and other products which are rich with iodine (236 people, $17.4 \%$, 95\% CI 11.1-23.7\%). And medical workers mentioned iodized salt consumption as a way to prevent iodine deficiency disorders statistically significantly more frequently, that respondents without medical education; and as for sea food consumption, they mentioned it statistically significantly less frequently than people from group 1.

Therefore, we can observe there is lower awareness about IDD-related issues as well as ways to prevent them both among population as a whole, and medical workers as well.

Although only $48.7 \%$ (95\% CI 48.1$49.3 \%$ ) stated they permanently consumed iodized salt, objectively it is consumed in much greater quantities and it is confirmed by volumes of its sales in retail networks. As per monitoring data collected in 2016-2017, io- dized salt sales accounted for $71.2 \%-81.5 \%$ of overall salt sales, and it didn't include sales of salt with natural iodine contents (for example, sea salt). Such sales volumes are due to sufficient manufacture of rock salt and table salt in the country which are the most popular salt types among consumers and due to relatively high prices on imported salt as well. We should take into account that in some regions iodized salt accounts for 70$90 \%$ of the overall salt volumes sold through retail networks. And for comparison, if we look at countries where "people are free to choose which salt to consume", only $50-60 \%$ respondents state they permanently consume iodized salt $[13,14,15]$.

At present a lot of food products enriched with iodine are manufactured in Belarus. Bearing that in mind, it was particularly important to take into account all possible sources of iodine as well as conditions for persistent and sufficient iodine consumption by population, on one hand, and to reveal probable excess introduction of the examined micronutrient, on the other hand. We substantiated different models for assessing iodine introduction with food (Table 3) [16]. 
Table 3

Models for assessing alimentary iodine introduction

\begin{tabular}{|c|l|l|}
\hline Model & \multicolumn{1}{|c|}{ Iodine contents } & \multicolumn{1}{c|}{ Consumption } \\
\hline Model 1 & $\begin{array}{l}\text { Natural in all groups of food } \\
\text { products }\end{array}$ & $\begin{array}{l}\text { Average consumption (median) of all food products } \\
\text { High level (90-95 percentile) of food products consumption } \\
\text { for all groups }\end{array}$ \\
\hline Model 2 & $\begin{array}{l}\text { Natural in some food products; } \\
\text { sausages and bakery are made } \\
\text { with using iodized salt }\end{array}$ & $\begin{array}{l}\text { Average consumption (median) of all food products } \\
\text { High level }(90-95 \text { percentile) of food products consumption } \\
\text { for all groups }\end{array}$ \\
\hline & $\begin{array}{l}\text { Natural in some food products; } \\
\text { sausages are made with using } \\
\text { iodized salt; bakery and dairy } \\
\text { products are made with using } \\
\text { iodized salt or iodcasein, eggs are } \\
\text { biologically enriched with iodine }\end{array}$ & $\begin{array}{l}\text { Average consumption (median) of all food products, a share } \\
\text { of enriched food products may account for 10, 50 and 100\% } \\
\text { of the overall food consumption }\end{array}$ \\
& $\begin{array}{l}\text { High level (90-95 percentile) of food products consumption } \\
\text { for all groups, a share of enriched food products may account } \\
\text { for 10,50 and 100\% of the overall food consumption }\end{array}$ \\
\hline
\end{tabular}

Iodine introduction estimated as per Model 1 gave us average consumption with food equal to only $92 \mu \mathrm{g}$ a day and it was only $60 \%$ of the physiological need ( $150 \mu \mathrm{g}$ a day). But if we take high levels of consumption within the same model, iodine contents in a daily ration go up to $234.2 \mu \mathrm{g}$ a day and it is even greater than the physiological need. However, this model is far too theoretical and unlikely to be met in practice, only in case of people who keep a specific high-calorie diet (for example, sportsmen).

As application of iodized salt in food products manufacturing is fixed in the national legislation of Belarus ${ }^{2}$, iodine introduction with food is more likely to occur according to Model 2. Iodine contents here amount to $157.4 \mu \mathrm{g}$ a day when food consumption is average and to $449.3 \mu \mathrm{g}$ a day when food consumption level is high. If we apply exaggerated scenarios (Model 3) and assume that a consumer uses 5 extra grams of iodized salt adding it to cooked food, we naturally see further increase in iodine contents in daily consumption, within 366-879.9 $\mu \mathrm{g}$ a day range. It still doesn't exceed the upper limit of safe iodine consumption $(1,100 \mu \mathrm{g}$ a day).

It is necessary to monitor iodized salt consumption as it helps to guarantee that population consumes this element in sufficient quantities, especially when there are a lot of recommendations to reduce salt consumption. WHO experts note that a decrease in sodium quantities consumed with salt is a direct economically efficient health preservation technique as it potentially allows to reduce incidence and mortality caused by certain noninfectious diseases and to lower expenses on medical care. According to these recommendations, at present adults are to reduce their daily sodium consumption to 2 grams that corresponds to 5 grams of salt (and it concerns all adults, both with primary hypertension and without it); as for children, maximum consumption recommended for them should be adjusted as per their need in energy and it will be substantially lower relative to adults' needs $[17,18,19]$.

Any research on iodine consumption based on calculated values should be confirmed by objective data on provision with iodine. Actual provision with iodine can be validated with assessment of iodine excretion with urine and dynamics in thyroid gland diseases caused by iodine deficiency. Figure 1 shows results of monitoring over iodine excretion with urine starting from 2001. The data prove there is no iodine deficiency as ioduria median

\footnotetext{
${ }^{2}$ Sanitary standards and rules entitled "Requirements to food raw materials and food products" approved by the Order issued by the Belarus Public Healthcare Ministry on June 21, 2013 No. 52. - Minsk, 2013. [web-source]. - URL: http://rcheph.by/news/postanovlenie-52-ot-21-iyunya-2013-g-ob-utverzhdenii-sanitarnykh-norm-_1386688238.html (date of visit November 20, 2018).
} 


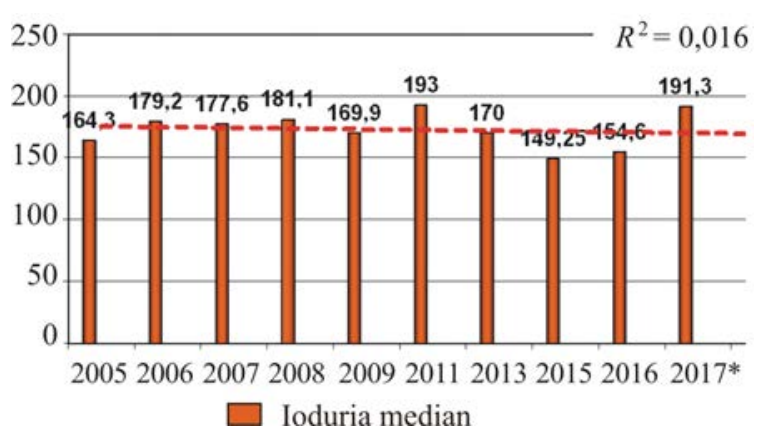

Figure 1. Monitoring over iodine excretion with urine in representative groups of children living in Belarus (2001-2017)

in children is higher than $100 \mu \mathrm{g} / \mathrm{l}$ in all the accomplished examinations.

There is another one reliably estimated parameter related to provision with iodine; it is prevalence of simple goiter in the overall population and among children younger than 18 as this thyroid gland disease is caused by iodine deficiency. Incidence rate for simple goiter decreased from 325.0 per 100 thousand people in 2000 to 51.51 per 100 thousand people in 2017 (Figure 2). An authentic, though less significant, decrease in incidence rate was registered among children younger than 18; it amounted to 136.31 per 100 thousand people.

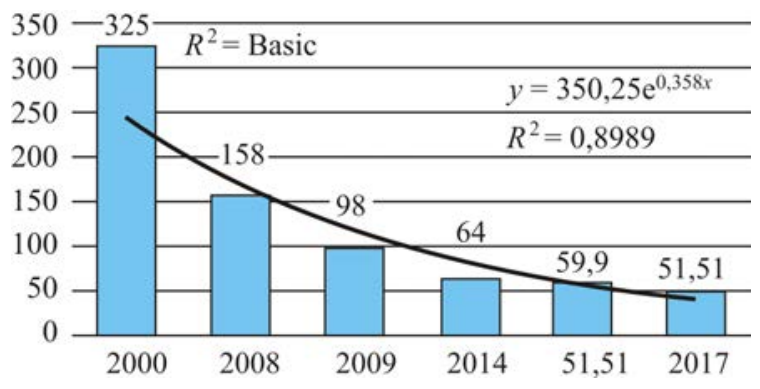

Figure 2. Dynamics in incidence rate for simple goiter (per 100 thousand people) over 2000-2017

Morbidity with primary congenital hypothyroidism diagnosed as per data obtained via neonatal screening is applied as an exact indicator for nutritional provision with iodine among newborns and their mothers [20]. In Belarus neonatal screening is performed in accordance with the consensus reached by the The European Society for Pediatric Endocrinology [21]. Frequency of congenital thyroid dysfunctions detected in a country amounts to such a value that proves there is no iodine deficiency in Belarus as it is equal to those detected in other European countries where iodine deficiency is also absent. In 2014 it amounted to 1:4,216 newborns out of 118,064 children (totally 118,697 children were born). The second screening stage also revealed positive trends; incidence with congenital hypothyroidism was equal to 1.96 per 100 thousand people in 2006, but it didn't exceed 0.94 per 100 thousand people in 2017.

Conclusion. The complex research which we performed is a convincing evidence that the national program aimed at eliminating IDD is quite efficient and it allows Belarus to maintain a status of a country with relevant iodine consumption. The chosen strategy that envisages obligatory use of iodized salt in food manufacturing and catering as it is fixed in the national legislation allows to provide sufficient iodine introduction with food and secures a margin necessary for a decrease in salt consumption by population. And here there is no risk related to excess introduction of iodine with food products enriched with this element. Nevertheless, questioning performed among population revealed that awareness about IDD issues decreased both among population in general and among medical workers as well; they were also less aware about a contribution made by iodized salt into IDD prevention. Some people believe that sporadic consumption of food products with high iodine contents, consumption of BAA to food, or replacing simple salt with natural sea salt to a great extent provide iodine deficiency prophylaxis. Given that, a certain deterioration of iodine provision among populations is rather probable and it may occur in the nearest future.

If population is informed about risks, it will allow, together with other strategic activities (medical and hygienic monitoring), to implement persistent strategy aimed at eliminating iodine deficiency in Belarus. We should take into account basic sources of information that people prefer to use, basically they are medical personnel and mass media, including the Internet. 
Our complex research convincingly proves that the national program aimed at eliminating iodine deficiency is quite efficient and it allows Belarus to maintain a status of a country where population consumes iodine in proper amounts. The chosen strategy that envisages obligatory use of iodized salt in food manufacturing and catering as it is fixed in the national legislation allows to provide sufficient iodine introduction with food and secures a margin necessary for a decrease in salt consumption by population. And here there is no risk related to excess introduction of iodine with food products enriched with this element.

Nevertheless, certain data indicate that both population in general and medical workers as well are now not properly aware about issues related to iodine deficiency and they don't fully comprehend a key role that iodized salt plays in prevention of the above men- tioned IDD. If this trend persists and people continue to be poorly aware about efficient prevention activities it will lead to a probable decrease in the existing iodine provision among population, Negative outcomes may be an increase in morbidity with IDD. Consequently, it is vital to activate an information campaign aimed at both population in general and medical workers which will be implemented via the most efficient up-to-date communication means (social networks, the Internet, etc.). All the above mentioned, together with activities implemented in the sphere of hygienic and medical monitoring, will help to preserve long-term stability in the national system for iodine deficiency prevention.

Funding. The research was not granted any sponsor support.

Conflict of interests. The authors state there is no any conflict of interests.

\section{References}

1. Zimmermann M.B. Iodine deficiency in industrialised countries. Geographical and geological influences on nutrition. Proceedings of the Nutrition Society, 2010, no. 69, pp. 133-43. DOI: $10.1017 / \mathrm{s} 0029665109991819$

2. A guide for program managers. Assessment of iodine deficiency disorders and monitoring their elimination.World Health Organization, UNICEF, ICCIDD, 2008, vol. 3, 98 p. Available at: http:// www.who.int/nutrition/publications/micronutrients/iodine deficiency/9789241595827/en/ (08.11.2018).

3. GerasimovG.A.OnovykhrekomendatsiyakhVOZiYuNISEFpoprofilaktikeyododefitsitnykhzabol evaniy [About New Recommendation of WHO and UNISEF for prevention of Iodine Deficiency Disorders]. Klinicheskayaieksperimental'nayatireoidologiya, 2008, vol. 4, no. 1, pp. 2-7 (in Russian).

4. Pearce E.N., Andersson M., Zimmermann M.B. Global iodine nutrition: Where do we stand in 2013? Thyroid, 2013, vol. 23, no. 5, 523 p. DOI: 10.1089/thy.2013.0128

5. Prete A., ParagliolaR.M., Corsello M. Iodine Supplementation: Usage "with a Grain of Salt". International Journal of Endocrinology, 2015, no. 312305, pp. 1-8. DOI:10.1155/2015/312305

6. Kolomiets N.D., Mokhort T.V., Fedorenko E.V. [et al.]. Problemadefitsitayodaiputieeresheniya v Respublike Belarus' [The problem of Iodine Feficiency and its Solution in the Republic of Belarus].Gigienaisanitariya, 2016, no. 5, pp. 417-422 (in Russian).

7. Mokhort T.V., Kolomiets N.D., Petrenko S.V., Fedorenko E.V., Mokhort E.G. Dinamicheskii monitoring yodnoiobespechennosti v Belarusi: rezul'tatyiproblemy [Dynamic monitoring of iodine sufficiency in Belarus: results and problems]. Problemyendokrinologii, 2018, vol. 64, no. 3, pp. 170-179 (in Russian).

8. Gerasimov G.A., vanderHaar F., Lazarus J.H. Obzor vozmozhnykh strategii profilaktiki yodnogo defitsita v stranakh Yugo-Vostochnoi Evropyi Tsentral'noi Azii: 2009-2016 [Overview of Iodine Deficiency Prevention Strategies in the South-Eastern Europe and Central Asia Region: 2009-2016]. Klinicheskayaieksperimental'nayatireoidologiya, 2017, vol. 13, no. 4, pp. 16-22 (in Russian).

9. Fortification of food-grade salt with iodine for the prevention and control of iodine deficiency disorders. World Health Organization, 2014, 45 p. Available at:http://www.who.int/nutrition/publications/guidelines/fortification_foodgrade_saltwithiodine/en/ (07.11.2018).

10. Völzke H., Caron P., Dahl L., de Castro J. [et al.]. Ensuring Effective Prevention of Iodine Deficiency Disorders. Thyroid, 2016, vol. 26, no. 2, pp. 189-196. DOI: 10.1089/thy.2015.0543 
11. Lee S.Y., Chang D.L., He X. [et al.]. Urinary iodine excretion and serum thyroid function in adults after iodinated contrast administration. Thyroid, 2015, vol. 25, no. 5, pp. 471-477. DOI: $10.1089 /$ thy.2015.0024

12. IDD NEWSLETTER, 2006, vol. 23, no. 2. Available at: http://www.ign.org/cm_data/IDD-NL2006-2.pdf (07.11.2018).

13. Soboleva D.E., Dora S.V., Karonova T.L. [et al.]. Otsenka effektivnosti profilaktiki defitsita yoda u vzroslogo naseleniya Sankt-Peterburga [Assessment of iodine profhylaxis effectiveness in adult population of Saint Petersburg]. Consilium Medicum, 2017, vol. 19, no. 4, pp. 65-69 (in Russian).

14. Mel'nichenko G.A., Troshina E.A., Platonova N.M. [et al.]. Osvedomlennost' naseleniya Rossii o yododefitsitnykh zabolevaniyakh i sposobakh ikh profilaktiki [The awareness of Russians about iodine deficiency diseases and methods of it's prevention]. Klinicheskaya i eksperimental'naya tireoidologiya, 2016, vol. 12, no. 3, pp. 25-30 (in Russian).

15. Pastorelli A.A., Stacchini P., Olivieri A. Daily iodine intake and the impact of salt reduction on iodine prophylaxis in the Italian population. European Journal of Clinical Nutrition, 2015, vol. 69, no. 2, pp. 211-215. DOI: 10.1038/ejen.2014.206

16. Fedorenko E.V., Kolomiets N.D., Mokhort T.V. [et al.]. Metodologiya otsenki riska zdorov'yu, assotsiirovannogo s obogashcheniem pishchevoy produktsii (na primere yoda) [Methodology for Health Risk Assessment Associated with the Fortified Food (iodine as an example)]. Sovremennyeproblemysostoyaniyaievolyutsiitaksonovbiosfery. Moscow, GEOKhI RAN Publ., 2017, no. 26, pp. 157-162 (in Russian).

17. Harding K.B., Peña-Rosas J.P., Webster A.C. [et al.]. Iodinesupplementation for women during the preconception, pregnancy and postpartum period. The Cochrane database of systematic reviews, 2017, no. 3. DOI: 10.1002/14651858.cd011761.pub2

18. K.S. Knust, A.M. Leung. Iodine: Basic Nutritional Aspects. Molecular, Genetic, and Nutritional Aspects of Major and Trace Minerals, 2017, pp. 133-141. Available at: https://www.sciencedirect.com/science/article/pii/B9780128021682000117 (21.11.2018).

19. Sullivan K.M., Perrine C.G., Pearce E.N., Caldwell K.L. Monitoring the iodine status of pregnant women in the United States. Thyroid, 2013, vol. 23, no. 4, pp. 520-521. DOI: 10.1089/thy.2012.0217

20. Zimmermann M.B., Aeberli I., Torresani T., Bürgi H. Increasing the iodine concentration in the Swiss iodized salt program markedly improved iodine status in pregnant women and children: a 5-y prospective national study. The American Journal of Clinical Nutrition, 2005, vol. 82, no. 2, pp. 388-392. DOI: $10.1093 /$ ajen.82.2.388

21. Léger J., Olivieri A., Donaldson M. [et al.]. European Society for Paediatric Endocrinology consensus guidelines on screening, diagnosis, and management of congenital hypothyroidism.The Journal of Clinical Endocrinology \& Metabolism, 2014, vol. 99, no. 2, pp. 363-384. DOI: 10.1210/jc.2013-1891

Phedorenko E.V., Kolomiets N.D., Mokhort T.V., Volchenko A.N., Mokhort E.G., Petrenko S.V., Sychik S.I. Risk communication as a component that provides stability of strategy aimed at eliminating diseases caused by iodine deficiency in Belarus. Health Risk Analysis, 2019, no. 1, pp. 58-67. DOI: 10.21668/health.risk/2019.1.06.eng

Received: 02.02.2019

Accepted: 24.02 .2019

Published: 30.03.2019 